\title{
The Quality of Life of Children with and Without Lip and Palate Clefts Before and After Dental Treatment Using the Moroccan Version of ECOHIS
}

\author{
Sarah Saif, Zineb. Serhier, Farid Bourzgui \\ ${ }^{1}$ Resident, Department of orthodontics, faculty of dentistry, University of Hassan II, Casablanca, Morocco \\ 2Professor and Head of the Department of orthodontics, faculty of dentistry, University of Hassan II.
} Casablanca, Morocco.

\section{ABSTRACT}

Objective : Assessement of the oral health related quality of life of moroccan children with and without lip and palate clefts (CLP),before and after dental treatment using the Moroccan version of ECOHIS (early childhood oral health impact scale) : M-ECOHIS

Patient And Method : Cross-sectional case-control study was conducted in a sample of 78children with CLP and their families within Operation smile Morocco and a control group of 97 children consulting in private dental practices, and the treatment outcomes in the same groups. Children's data were collectedusing the M-ECOHIS questionnaire.

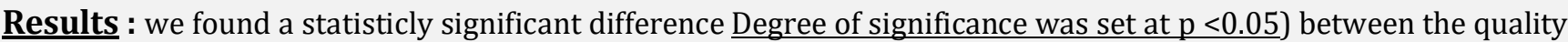
of life of children with and without clefts in the overall M-ECOHIS scores and its subclasses. Before the treatment, the child Impact section showed a remarkable difference between these groups in the areas related to pain, difficulty in eating and drinking, difficulty in speaking and smiling. With regard to the difficulties faced by children with clefts, the question "Difficult to pronounce the words" obtained the highest mean score. The family section showed a statisticly significant(give the $p$ founded) in financial difficulty. significant differences were found in the child impact section after dental treatment in all items except the difficulty in eating and drinking, for the difficulties experienced by the family, the financial impact scored the highest mean score (give the score). No significant differences were found between gender and sex, socio-economic status, mother's educational level and oral status and the type of the cleft.

Conclusion : This study allowed us to assess the effectiveness of the M-ECOHIS questionnaire, and to highlight the differences in the quality of life between patients with and without cleft lip and palate before and after the treatment

Keywords : Quality of life, cleft lip and palate, evaluation, validation, treatment, Morocco.

\section{Introduction}

The relationship between oral health and the quality of life has gained a growing attention in dentistry due to the problems resulting in physical and psychological impacts on people's lives(1).Oral health problems can cause pain, discomfort, suffering, impairment of functions such as eating, chewing ,smiling, communictaion and other esthetic problems leading to significant impact on the quality of life (QoL)(2).

The oral health of children affects feeding, smiling, speaking, and socialization. In fact, facial appearance and its relation with body image, self-esteem,and emotional well-being have a great impact on social interactions. Thus, negative feelings related to facial appearancemake the child believe that oral health negatively influences their everyday life activities(1)

Moreover succesful treatments in children are not defined in terms of cure, remission and improvement of the QoL particularly in children with cranio-facial abnormalities such as oral clefts (2). Infact, oral clefts occure in 1/700 live human births worldwide (3) and these abnormalities have a great impact on all aspects of both patient's lives and their families. In addition to the esthetical impact, CLP deformities are associated with a number of problems such as hearing deficit, speech disorders , chronic ear infections (otitis media ), dental and psychological problems. (4-2) 
Several studies assessed the impact of caries, tooth trauma, and malocclusion on the QoL of preschool children and their families using the ECOHIS and found that dental caries and traumatic dental injury came withan impact on the OHRQoL of these children and their families (5-2). However, only few studiesrevealed that CLP impacted negatively the QoL of preschool children and their families using the ECOHIS.(2)

Therefore, this study aimed to assess the QoL using the M-ECOHIS in children under 6 years old with CLP and compare it with apair group of children without CLP before and after ongoing dental treatment.

\section{Patients and Method}

We conducted a cross-sectional study within Operation Smile Morocco (a humanitarian medical organization that provides care for patients with CLP) and a number of randomly selected private dental practices based in Casablanca.

Were included in this study both moroccan preschool children without CLP attending private dental practices for routine dental care and children with CLP treated within operation Smile Morocco.

Informed consent was obtained from the parents of the two groups.And the M-ECOHIS version was used to assess the quality of life of these children (6).

Our study was approved by the ethical review board of the dental school, University Hassan II Casablanca, Morocco. All the parents interviewed in this study completed the M-ECOHIS questionnaire.Data analysis was performed using SPSS Inc., Chicago, Ill., USA and standard deviation for means with a degree of significance set at $\mathrm{p}<0.05$.

\section{Results}

175 childrenaged under 6 years and their parents (78 children with cleft lip and palate consulting at Operation Smile Morocco and 97 children without clefts consulting in private practices for routine care acts)participated in this study. The mean age of the overall sample was 4,429 years $( \pm 0.9748)$ and, the mean age of children without clefts was $4,81( \pm 0.682)$ while children with CLP were with a mean age of $3,94( \pm 1,166)$

The majority of the parents belonged to a low socio-economic class. The annual income of families, was less than 15000 Moroccan dirhams (MAD)for $62.9 \%$ of the families in the 2 groups ( $1 €$ is converted on average to 11 MAD). Approximately $39 \%$ of the mothers in the overall sample and the 2 groups were without a diploma, and $25 \%$ of the mothers had a primary educational level(Table1), 53.7\% of the children participating in our study had never visited the dentist. While $29.1 \%$ visited the dentist in less than a year. Among the treatments provided to children who had already visited the dentist, restorative treatments were the most frequently reported with $78.3 \%$ followed by pulpotomies and pulpectomy and lastly the extractions(Table 2). The Early Childhood Caries (ECC) indexin our overall sample ranges from 0 to 23 with a mean of $7,28( \pm 3,76)$.

\begin{tabular}{|l|c|c|c|}
\hline & $\begin{array}{c}\text { Overall sample } \\
\mathbf{N = 1 7 5}\end{array}$ & $\begin{array}{c}\text { Children with CLP } \\
\mathbf{N = 7 8}\end{array}$ & $\begin{array}{c}\text { Children without } \\
\text { CLP N=97 }\end{array}$ \\
\hline Age (mean+- SD) & $4,429( \pm 0,974)$ & $3,94( \pm 1,166)$ & $4,81( \pm 0,682)$ \\
\hline Sex Male & $\mathbf{7 8 ( 4 4 . 6 \% )}$ & $45(57,7 \%)$ & $\mathbf{5 2 ( 5 3 , 6 \% )}$ \\
\hline Female & $\mathbf{9 7}(55.4 \%)$ & $33(42,3 \%)$ & $\mathbf{4 5 ( 4 6 , 4 \% )}$ \\
\hline $\begin{array}{l}\text { Socio Economic } \\
\text { level of the Father }\end{array}$ & & & \\
\hline High & $\mathbf{1 0 ( 5 . 7 \% )}$ & $1(1,3 \%)$ & $\mathbf{9 ( 9 , 3 \% )}$ \\
\hline Average & $\mathbf{1 5 ( 8 . 6 \% )}$ & $3(3,8 \%)$ & $\mathbf{7 6 ( 7 8 , 4 \% )}$ \\
\hline Low & $\mathbf{1 5 0 ( 8 5 . 7 \% )}$ & $74(94,9 \%)$ & \\
\hline $\begin{array}{l}\text { Level of Education } \\
\text { of the Mother }\end{array}$ & & & $\mathbf{3 8 ( 3 9 , 2 \% )}$ \\
\hline Without Diploma & $\mathbf{6 9 ( 3 9 . 4 \% )}$ & $31(39,7 \%)$ & $\mathbf{2 6 ( 2 6 , 8 \% )}$ \\
\hline Primary & $\mathbf{4 5 ( 2 5 . 7 \% )}$ & $19(24,4 \%)$ & \\
\hline
\end{tabular}




\begin{tabular}{|l|c|c|c|}
\hline Secondary & $43(24.6 \%)$ & $21(26,9 \%)$ & $22(22,7 \%)$ \\
\hline Post-graduate & $18(10.3 \%)$ & $7(9 \%)$ & $11(11,3 \%)$ \\
\hline $\begin{array}{l}\text { Annual Income of } \\
\text { the Parents/DH }\end{array}$ & & & \\
\hline$<15000$ & $110(62.9 \%)$ & $49(62,8 \%)$ & $61(62,9 \%)$ \\
\hline $15000-30000$ & $47(26.9 \%)$ & $25(32,1 \%)$ & $22(22,7 \%)$ \\
\hline $30000-60000$ & $11(6.3 \%)$ & $4(5,1 \%)$ & $7(7,2 \%)$ \\
\hline $60000-120000$ & $6(3.4 \%)$ & $0(0 \%)$ & $6(6,2 \%)$ \\
\hline$>120000$ & $1(6 \%)$ & $0(0 \%)$ & $1(1,0 \%)$ \\
\hline & & & \\
\hline
\end{tabular}

Table1: Socio-demographic characteristics of the participants

\begin{tabular}{|c|c|c|}
\hline Last visit to the Dentist & $\mathbf{N}$ & $\mathbf{\%}$ \\
\hline$<1 \mathrm{yr}$ & 51 & $29.1 \%$ \\
\hline $1-2 \mathrm{yrs}$ & 15 & $8.6 \%$ \\
\hline $2-5 \mathrm{yrs}$ & 15 & $8.6 \%$ \\
\hline$>5 \mathrm{yrs}$ & 94 & $53.7 \%$ \\
\hline Total & 175 & $100 \%$ \\
\hline
\end{tabular}

\begin{tabular}{|c|c|c|}
\hline $\begin{array}{c}\text { Treatments } \\
\text { Restauration }\end{array}$ & $\mathbf{N}$ & $\mathbf{\%}$ \\
\hline Yes & 137 & $\mathbf{7 8 . 3}$ \\
\hline No & 38 & $\mathbf{2 1 . 7}$ \\
\hline Total & 175 & $\mathbf{1 0 0 \%}$ \\
\hline Pulpotomy /Pulpectomy & & $\mathbf{8 5 . 7}$ \\
\hline Yes & 150 & 13.7 \\
\hline No & 24 & $\mathbf{1 0 0} \%$ \\
\hline Total & 175 & 22.9 \\
\hline Extraction & & 77.1 \\
\hline Yes & 40 & $100 \%$ \\
\hline No & 135 & 175 \\
\hline
\end{tabular}

Table 2: last visit to the dentist and the treatments underwent by the children's hospital

Table 3 depicts the the number and (percentage) of the M-ECOHIS scores with its subclasses.

Before dental treatment, items related to pain (30.3\%), difficulty eating (29.7\%), irritation (32.6\%), were the most frequently reported in the section impact on the child.

The item related to financial distress has often been reported in the section impact on the family.

The impact score on the child was greater than that on the family in both groups 
Table 3: ECOHIS scores before the treatment

\begin{tabular}{|c|c|c|c|c|c|c|}
\hline Scores Items & Never & Hardly ever & Ocasionally & Often & Very often & Don't know \\
\hline & $N(\%)$ & $N(\%)$ & $N(\%)$ & $N(\%)$ & $N(\%)$ & $N(\%)$ \\
\hline \multicolumn{7}{|l|}{$\begin{array}{l}\text { Child Impact Section } \\
(\mathrm{n}=175)\end{array}$} \\
\hline Oral/dental pain & $43(24.6)$ & $20(11.4)$ & $52(29.7)$ & $53(30.3)$ & $7(4.0)$ & \\
\hline $\begin{array}{l}\text { Difficulty in } \\
\text { drinking }\end{array}$ & $52(29.7)$ & $31(17.7)$ & $60(34.3)$ & $29(16.6)$ & $3(1.7)$ & \\
\hline Difficulty in eating & $52(29.7)$ & $42(24.0)$ & $52(29.7)$ & $24(13.7)$ & $5(2.9)$ & \\
\hline $\begin{array}{l}\text { Difficulty in } \\
\text { pronouncing words }\end{array}$ & $66(37.7)$ & $30(17.1)$ & $18(10.3)$ & $41(23.4)$ & $20(11.4)$ & \\
\hline $\begin{array}{l}\text { Missed pre-school } \\
\text { or school }\end{array}$ & $94(53.7)$ & $29(16.6)$ & $34(19.4)$ & $10(5.7)$ & $4(2.3)$ & $4(2.3)$ \\
\hline Trouble sleeping & $55(31.4)$ & $34(19.4)$ & $37(21.1)$ & $44(25.1)$ & $4(2.3)$ & $1(0.6)$ \\
\hline $\begin{array}{l}\text { Irritable or } \\
\text { frustrated }\end{array}$ & $27(15.4)$ & $25(14.3)$ & $38(21.7)$ & $57(32.6)$ & $28(16.0)$ & \\
\hline $\begin{array}{l}\text { Avoided smiling or } \\
\text { laughing }\end{array}$ & $84(48.0)$ & $69(39.4)$ & $14(8.0)$ & $7(4.0)$ & $1(0.6)$ & $1(0.6)$ \\
\hline Avoided talking & $91(52.0)$ & $63(36.0)$ & $12(6.9)$ & $9(5.1)$ & $0(0)$ & \\
\hline \multicolumn{7}{|l|}{$\begin{array}{l}\text { Family Impact } \\
\text { Section } \quad(n=175)\end{array}$} \\
\hline Been upset & $58(33.1)$ & $49(28.0)$ & $38(21.7)$ & $21(12.0)$ & $9(5.1)$ & \\
\hline Felt guilty & $63(36.0)$ & $43(24.6)$ & $40(22.9)$ & 21(12.0) & $8(4.6)$ & \\
\hline Time off work & $63(36.0)$ & $43(24.6)$ & $40(22.9)$ & $21(12.0)$ & $8(4.6)$ & $1(0.6)$ \\
\hline Financial impact & $29(16.6)$ & $22(12.6)$ & $41(23.4)$ & $59(33.7)$ & $1(0.6)$ & $1(0.6)$ \\
\hline
\end{tabular}

However, after dental treatment oral pain and difficulty in eating and drinking were still reported but in a more subtle way added to the trouble in sleeping and feeling frustrated, all the four items were frequently reported in the family impact section . (Table 4) 
This study showed a total mean score of $17,737( \pm 8,0021)$, in the overall sample, the child impact score was 11,926 $( \pm 5.5564)$.For the children without CLP, the mean child impact score was $10.94( \pm 5.381)$,andthe mean family impact score was 5,823. (Table 5)

\begin{tabular}{|c|c|c|c|c|c|}
\hline Scores Item & Never & Hardly ever & Ocasionally & Often & Very often \\
\hline & $N(\%)$ & $N(\%)$ & $N(\%)$ & $N(\%)$ & $N(\%)$ \\
\hline \multicolumn{6}{|l|}{$\begin{array}{l}\text { Child Impact Section } \\
(\mathrm{n}=175)\end{array}$} \\
\hline Oral/dental pain & $48(27.4)$ & $86(49.1)$ & $36(20.6)$ & $5(2.9)$ & $0(0)$ \\
\hline Difficulty in drinking & $58(33.1)$ & $90(51.4)$ & $26(14.9)$ & $1(0.6)$ & $0(0)$ \\
\hline Difficulty in eating & $58(33.1)$ & $95(54.3)$ & $19(10.9)$ & $1(.6)$ & $2(1.1)$ \\
\hline $\begin{array}{l}\text { Difficulty in } \\
\text { pronouncing words }\end{array}$ & $79(45.1)$ & $45(25.7)$ & $27(15.4)$ & $21(12.0)$ & $3(1.7)$ \\
\hline $\begin{array}{l}\text { Missed pre-school or } \\
\text { school }\end{array}$ & $113(64.6)$ & $50(28.6)$ & $10(5.7)$ & $1(0.6)$ & $1(0.6)$ \\
\hline Trouble sleeping & $62(35.4)$ & $61(34.9)$ & $40(22.9)$ & $12(6.9)$ & $12(6.9)$ \\
\hline Irritable or frustrated & $32(18.3)$ & $45(25.7)$ & $79(45.1)$ & 19(10.9) & $0(0)$ \\
\hline $\begin{array}{l}\text { Avoided smiling or } \\
\text { laughing }\end{array}$ & $91(52.0)$ & $74(42.3)$ & $10(5.7)$ & $0(0)$ & $0(0)$ \\
\hline Avoided talking & $94(53.7)$ & $73(41.7)$ & $8(4.6)$ & $0(0)$ & $0(0)$ \\
\hline $\begin{array}{l}\text { Family Impact } \\
\text { Section } \quad(\mathrm{n}=175)\end{array}$ & & & & & \\
\hline Been upset & $67(38.3)$ & $69(39.4$ & $35(20.0)$ & $4(2.3)$ & $0(0)$ \\
\hline Felt guilty & $66(37.7)$ & $70(40.0)$ & $35(20.0)$ & $4(2.3)$ & $0(0)$ \\
\hline Time off work & $71(40.6)$ & $61(34.9)$ & $35(20.0)$ & $8(4.6)$ & $0(0)$ \\
\hline Financial impact & $24(13.7)$ & $24(13.7)$ & $59(33.7)$ & $45(25.7)$ & $8(4.6)$ \\
\hline
\end{tabular}

Table 4: ECOHIS scores after the treatment 


\section{Mean $\pm s d$}

\begin{tabular}{|c|c|c|c|c|}
\hline & & Child impact & Family impact & Total \\
\hline \multirow[t]{2}{*}{$N=175$} & Before & $11.926( \pm 5.5564)$ & $5.823( \pm 0.0021)$ & $17.737( \pm 8.0021)$ \\
\hline & After & $7.531( \pm 4.4045)$ & $4.463( \pm 2.7223)$ & $11.943( \pm 6.5062)$ \\
\hline \multirow[t]{2}{*}{$N=97$} & Before & $10,94( \pm 5,381)$ & $5,25( \pm 3,606)$ & $16,14( \pm 8,021)$ \\
\hline & After & $5,76( \pm 3,570)$ & $3,74( \pm 2,412)$ & $9,41( \pm 5,358)$ \\
\hline \multirow[t]{2}{*}{$N=78$} & Before & $13,15( \pm 5,560)$ & $6.538( \pm 3.5555)$ & $19.718( \pm 8.0208)$ \\
\hline & After & $9,73( \pm 4,371)$ & $5,36( \pm 2,833)$ & $15,09( \pm 6,463)$ \\
\hline
\end{tabular}

Table 5: Mean Ecohis scores

\section{Discussion}

The present study assessed the impact of dental disease and treatmentexperienceson the QoL of children with and without CLPand their families.A total of 175 children ( 97 children without clefts and 78 children with clefts) and their parents participated in the study.The mean age of the children in our sample was $4.429( \pm 0.9748)$, which is consistent with most studies conducted for the same target population, including the study by NS Ismail et al. which revealed an average age of $4.22(7)$

The mean age of children without CLPwas $4.81( \pm 0.682)$ while children with CLP were younger with a mean age of 3.94 ( \pm 1.166 ) Several studies have shown that children's oral health status is often linked to social dimensions, such as parents' income and education (8). The annual income was less than 15000 MAD for $62.9 \%$ of the families in our sample for the 2 groups which could influence the quality of life of the children belonging to these families. Indeed Kumar and al. reported a significant association between a high family income and a better predictibility of the quality of life among children. (9)

Cohen-Carneiro $\mathrm{F}$ et al. showed that the negative impact was more frequent among adults living in poorer regions or considered as poor, had a low-income or underprivileged (9), which is the case for our study where the majority of parents belonged to a low socio-professional class containing mostly non qualified technicians or workers.

The level of education of the mothers in our sample was often low, in fact approximately $39 \%$ of the mothers in the overall sample and the 2 groups were without a diploma, and only $25 \%$ of the mothers had a primary level of education.

Paradoxically, Kumar and al. found two studies that showed that mother's education, but not father's education, was significantly related to quality of life scores. In four studies, the mother or the guardian had a significant association with quality of life scores, along with three other studies, whitch revealed that a higher level of education of the mother significantly predicts a better perception of the children's quality of life. (9)

$53.7 \%$ of the children participating in our study have never visited the dentist. While $29.1 \%$ visited it in less than a year. Among the treatments provided to children who had already visited the dentist, restorative treatments were the most frequently reported followed by pulpotomies and pulpectomy and lastly the extractions.

In a study by Abanta J. and al. Treatment experiences and the presence of early childhood caries (ECC) were found to have a significant impact on the quality of life of preschool children and their families. Given that these children had previously requested dental treatment, one would think that they would score higher than those who did not 
seek dental care, which could lead to an overestimation of the results (10). This is not the case in our study where there was generally lowerM-ECOHIS mean scores after dental treatment.

The ECC index in our overall sample varies between 0 and 23 with an average of $7.28( \pm 3,76)$. As a result, it is clear that children's oral health status is poor, the $50 \%$ less caries oral health goal set by the WHO (world health organisation) is still far from being achieved.(we need ref)

Because public health programs do not cover the youngest children, their oral health is often neglected, leaving many children with ECCs and suffering from chronic pain and discomfort.

A survey that was conducted within Brazilian preschool children showed that almost $27 \%$ of children aged 18 to 36 months had at least one temporary tooth with caries [Ministry of Health Project SB Brazil, 2003].(ref)

In our study a nonsignificant association was found between the ECC index and the type of the CLP, unlike a study by Moura et al, which showed that children with bilateral cleft lip and palate had a higher percentage of caries compared to children with unilateral clefts (11-12). Indeed, the carious risk in children with clefts is influenced by poor hygiene, the presence of palatal fistulas, removable and fixed orthodontic appliances and the presence of dental abnormalities (supernumerary teeth, microdontia, geminations, structural abnormalities). Some children with cleft palate could use intraoral appliances right after birth. The benefits of these devices include food assistance and growth support and a good development of the palate. However, these devices could promote the early establishment of cariogenic bacteria in the oral cavity, increase acid production and increase the risk of caries destruction.(12)

This study showed a total overall M-ECOHIS score of $17,737( \pm 8,0021)$, which is higher than that found in the study conducted in Brazil as well as in Saudi Arabia in a study conducted by Pani et al. (14 -13)

The child impact score was 11,926 higher than a study by Sajadi et al. (13)4.07 ( \pm 0.79$)$, and a study by Scarpelli et al. $(2.6( \pm 3.3))(14)$

In addition, the average family impact score was 5.823, higher than the one found in the study by (M Zeraatkar et al.) (2) (3.2 \pm 0.83$)$ and Scarpelli (1.4 \pm 2.2$)(14-13)$

The impact score on the child is greater than that on the family with a statistically significant difference. This results are in agreement with the study by Zeraatkar et al.(2) where the impacts on children were statistically greater than those on the family. In parallel, in other studies, parents reported a greater impact on the quality of life of children compared to the quality of life of families, although these studies aimed some other oral disorders.(2) The mean scores of family and child impact scales are lower than those reported by M. Zeraatkar and al. In fact they reported a mean score of $(39.14 \pm 2.16)$ for the impact on the child and $(18.16 \pm 1.52)$ for the family impact.

According to the population studied, we found statistically significant differences in the impact of treatment on the quality of life of children and families (problems with days absent from work due to treatment and the financial impact of dental treatment on families of children) (15)(Table 6-7)

\begin{tabular}{|c|c|c|c|}
\hline & $\begin{array}{l}\text { Children without CLP } \\
\qquad(n=97)\end{array}$ & $\begin{array}{l}\text { Children with } \\
\text { CLP(n=78) }\end{array}$ & $p$ \\
\hline Child Impact Section & $10,94( \pm 5,381)$ & $13,15( \pm 5,560)$ & 0.008 \\
\hline Oral/dental pain & $2,12( \pm 1,063)$ & $1,35( \pm 1,298)$ & 0,000 \\
\hline Difficulty in drinking & $1,74( \pm 1,073)$ & $1,04( \pm 1,086)$ & 0,000 \\
\hline Difficulty in eating & $1,43( \pm 1,050)$ & $1,27( \pm 1,224)$ & 0,021 \\
\hline $\begin{array}{c}\text { Difficulty in } \\
\text { pronouncing words }\end{array}$ & $0,58( \pm 0,922)$ & $2,73( \pm 1,113)$ & 0,000 \\
\hline $\begin{array}{l}\text { Missed pre-school or } \\
\text { school }\end{array}$ & $1,00( \pm 1,173)$ & $0,85( \pm 1,320)$ & 0,337 \\
\hline Trouble sleeping & $1,40( \pm 1,222)$ & $1,60( \pm 1,313)$ & 0,445 \\
\hline Irritable or frustrated & $1,90( \pm 1,271)$ & $2,56( \pm 1,254)$ & 0,006 \\
\hline $\begin{array}{c}\text { Avoided smiling or } \\
\text { laughing }\end{array}$ & $0,55( \pm 0,878)$ & $0,90( \pm 0,783)$ & 0,000 \\
\hline Avoided talking & $0,47( \pm 0,792)$ & $0,87( \pm 0,812)$ & 0,000 \\
\hline Family Impact Section & $5,25( \pm 3,606)$ & $6,54( \pm 3,555)$ & 0.019 \\
\hline Been upset & $1,20( \pm 1,213)$ & $1,38( \pm 1,165)$ & 0,303 \\
\hline Felt guilty & $1,13( \pm 1,213)$ & $1,38( \pm 1,165)$ & 0,394 \\
\hline Time off work & $0,89( \pm 0,923)$ & $1,51( \pm 1,214)$ & 0,002 \\
\hline Financial impact & $2,06( \pm 1,413)$ & $2,28( \pm 1,138)$ & 0,010 \\
\hline TOTAL & $16,14( \pm 8,021)$ & $19.718( \pm 8.0208)$ & 0.003 \\
\hline
\end{tabular}

Table 6: Mean scores in patients with and without clefts before treatment 


\begin{tabular}{|c|c|c|c|}
\hline & $\begin{array}{l}\text { Children without } \\
\text { CLP (n=97) }\end{array}$ & $\begin{array}{c}\text { Children with CLP } \\
\quad(n=78)\end{array}$ & $p$ \\
\hline $\begin{array}{l}\text { Child Impact } \\
\text { Section }\end{array}$ & $5,76( \pm 3,570)$ & $9,73( \pm 4,371)$ & 0,001 \\
\hline Oral/dental pain & $1,07( \pm 0,753)$ & $0,88( \pm 0,789)$ & 0,078 \\
\hline $\begin{array}{c}\text { Difficulty in } \\
\text { drinking }\end{array}$ & $0,85( \pm 0,651)$ & $0,81( \pm 0,740)$ & 0,423 \\
\hline Difficulty in eating & $0,77( \pm 0,669)$ & $0,88( \pm 0,806)$ & 0,244 \\
\hline $\begin{array}{c}\text { Difficulty in } \\
\text { pronouncing words }\end{array}$ & $0,25( \pm 0,479)$ & $1,92( \pm 0,977)$ & 0,000 \\
\hline $\begin{array}{l}\text { Missed pre-school } \\
\text { or school }\end{array}$ & $0,37( \pm 0,583)$ & $0,53( \pm 0,785)$ & 0,073 \\
\hline Trouble sleeping & $0,65( \pm 0,708)$ & $1,46( \pm 0,976)$ & 0,000 \\
\hline $\begin{array}{l}\text { Irritable or } \\
\text { frustrated }\end{array}$ & $1,23( \pm 0,919)$ & $1,81( \pm 0,807)$ & 0,000 \\
\hline $\begin{array}{c}\text { Avoided smiling or } \\
\text { laughing }\end{array}$ & $0,31( \pm 0,487)$ & $0,82( \pm 0,619)$ & 0,000 \\
\hline Avoided talking & $0,29( \pm 0,478)$ & $0,78( \pm 0,595)$ & 0,000 \\
\hline $\begin{array}{c}\text { Family Impact } \\
\text { Section }\end{array}$ & $3,74( \pm 2,412)$ & $5,36( \pm 2,833)$ & 0,001 \\
\hline Been upset & $0,66( \pm 0,748)$ & $1,12( \pm 0,821)$ & 0,002 \\
\hline Felt guilty & $0,69( \pm 0,755)$ & $1,09( \pm 0,825)$ & 0,009 \\
\hline Time off work & $0,59( \pm 0,774)$ & $1,26( \pm 0,874)$ & 0,000 \\
\hline Financial impact & $1,73( \pm 1,195)$ & $2,00( \pm 0,940)$ & 0,002 \\
\hline TOTAL & $9,41( \pm 5,358)$ & $15,09( \pm 6,463)$ & 0,000 \\
\hline
\end{tabular}

Table 7: Mean scores in patients with and without clefts after treatment

A study by Novaes and al. (16) aimed at assessing the quality of life after dental treatment showed that scores vary with the duration of the reassessment. Post-treatment evaluation times were too diverse to draw firm conclusions (ranging from 7 days to one year). They observed a similarity when ECOHIS was applied 7 and 30 days after treatment. However, a slight decrease in the effect was observed after 90 days. This decrease could be explained by treatment failures or an expected temporal decrease in the perception of the importance of dental treatment. Interestingly, the study that observed the smallest effect of treatment via ECOHIS scores applied the questionnaire nearly a year after treatment. (17)

Parallely we found that the quality of life of children with CLP was statistically different from that of children without CLP, that is, the quality of life of children without CLP was greater than that of children with CLP, confirming the findings of Antonarakis, Patel and Tompson (2013). (18) These authors conducted a systematic review to assess the quality of oral health of non-syndromic individuals with CLP compared with individuals without CLP and observed that the quality of life was lower among the first. Antunes, et al. (2014) (19) analyzed, using the (B-FIS) scale, the impact of the quality of life on the families of children with non-syndromic CLP in comparison with children without CLP with respect to age, gender, geographic distribution, and socio-economic level. Children with CLP had a greater impact.

\section{Conclusion}

Based on the results of this study, the comparison of the 2 groups revealed that the presence of CLP had a negative impact on the quality of oral health of children under 6 years and their parents and that there was a statistically significant difference between the quality of life of children with and without CLP before and after dental treatment. 


\title{
Financial Support and Sponsorship : Nil
}

\author{
Acknowledgment \\ The Authors wish to thank everyone who took part of this study \\ The Authors declare that there is no conflict of interests
}

\section{References}

1. Rando, G. M., Jorge, P. K., Vitor, L. L. R., Carrara, C. F. C., Soares, S., Silva, T. C.\& Oliveira, T. M. (2018). Oral health-related quality of life of children with oral clefts and their families. Journal of Applied Oral Science, 26.

2. Zeraatkar, M., Ajami, S., Nadjmi, N., \& Golkari, A. (2018). Impact of oral clefts on the oral health-related quality of life of preschool children and their parents. Nigerian journal of clinical practice, 21(9), 11581163.

3. Bhandari, S., Soni, B. W., \& Saini, S. S. (2018). From birth till palatoplasty: Prosthetic procedural limitations and safeguarding infants with palatal cleft. Journal of Indian Society of Pedodontics and Preventive Dentistry, 36(1), 101.

4. Mitchell, J. C., \& Wood, R. J. (2000). Management of cleft lip and palate in primary care. Journal of Pediatric Health Care, 14(1), 13-19.

5. Gomes MC, Pinto-Sarmento TC, Costa EM, Martins CC, Granville-Garcia AF, Paiva SM, et al. Impact of oral health conditions on the quality of life of preschool children and their families: A cross-sectional study. Health Qual Life Outcomes $2014 ; 12: 55$.

6. Bourzgui, F., Saif, S., Serhier, Z., Diouny, S., \& Othmani, M. B. (2017). Adaptation and Validation of The Moroccan Arabic Version of the Early Childhood Oral Health Impact Scale (ECOHIS).

7. Ismail, N. S., Ghani, N. M. A., Supaat, S., Kharuddin, A. F., \& Ardini, Y. D. (2018). The Early Childhood Oral Health Impact Scale (ECOHIS): Assessment Tool in Oral Health-Related Quality of Life. Journal of International Dental and Medical Research, 11(1), 162-168.

8. Santhosh KJT, Prabu D, Suhas K: Socio-behavioral variables effecting oral hygiene and periodontal status of 12 year-old schoolchildren of Udaipur district. Odontostomatol Trop 2013, 36:27-33.

9. Kumar, S., Kroon, J., \& Lalloo, R. (2014). A systematic review of the impact of parental socio-economic status and home environment characteristics on children's oral health related quality of life, Health and quality of life outcomes, 12(1), 1.

10. Abanto, J., Carvalho, T. S., Mendes, F. M., Wanderley, M. T., Bönecker, M., \& Raggio, D. P. (2011). Impact of oral diseases and disorders on oral health-related quality of life of preschool children, Community dentistry and oral epidemiology, 39(2), 105-114

11. Moura AM, Andre M, Lopez MT, Dias RB. Prevalence of caries in Brazilian children with cleft lip and/or palate, aged 6 to 36 months, Braz Oral Res 2013; 27: 336-41.

12. Britton, K.F.M. \& Welbury, R.R.Dental caries prevalence in children with cleft lip/palate aged between 6 months and 6 years in the West of Scotland, Eur Arch Paediatr Dent (2010) 11: 236.

13. Sajadi, F. S., Pishbin, L., Azhari, S. H., \& Moosazadeh, M. (2015). Impact of Oral and Dental Health on Children's and Parents' Quality of Life Based on Early Childhood Oral Health Impact Scale (ECOHIS) Index, Int J Dent Sci Res, 3(2), 28-31.

14. Scarpelli, A. C., Oliveira, B. H., Tesch, F. C., Leão, A. T., Pordeus, I. A., \& Paiva, S. M. (2011). Psychometric properties of the Brazilian version of the early childhood oral health impact scale (BECOHIS), BMC oral health, 11(1), 19.

15. Rando, G. M., Jorge, P. K., Vitor, L. L. R., Carrara, C. F. C., Soares, S., Silva, T. C., ... \& Oliveira, T. M. (2018). Oral health-related quality of life of children with oral clefts and their families, Journal of Applied Oral Science, 26, http://dx.doi.org/10.1590/1678-7757-2017-0106

16. Novaes, T. F., Pontes, L. R. A., Freitas, J. G., Acosta, C. P., Andrade, K. C. E., Guedes, R. S., ... \& Mendes, F. M. (2017). Responsiveness of the Early Childhood Oral Health Impact Scale (ECOHIS) is related to dental treatment complexity, Health and quality of life outcomes, 15(1), 182.

17. Arrow P. Responsiveness and sensitivity of the Early Childhood Oral Health Impact Scale to primary dental care for early childhood caries, Community Dent Oral Epidemiol. 2016; 44:1-10. 
18. Kavand G, Younesian F, Saffar Shahroudi A, Dorri M, Akbarzadeh Baghban A, Khoshnevisan M, “Oral Health Related Quality of Life among Iranian children: Part I-Validity, reliability, prevalence and severity assessment of daily impact factors" J Dent Sch., 27, 187-196, 2010.

19. Acuña-González, G., Medina-Solís, C. E., Maupomé, G., Escoffie-Ramírez, M., Hernández-Romano, J., Márquez-Corona, M. D. L., ... \& Villalobos-Rodelo, J. J. (2011). Family history and socioeconomic risk factors for non-syndromic cleft lip and palate: a matched case-control study in a less developed country, Biomedica, 31(3), 381-391.

How to cite this Article: Sarah Saif, Z.Serhier, Farid Bourzgui, The quality of life of children with and without lip and palate clefts before and after dental treatment using the Moroccan version of ECOHIS.

Int. J. Drug Res. Dental Sci., 2019; 1(1):11-20.

Source of Support: Nil, Conflict of Interest: None declared. 